\title{
A Conceptual Model for Assistant Platforms
}

\author{
Rainer Schmidt \\ Munich University oaS \\ rainer.schmidt@hm.edu
}

\author{
Rainer Alt \\ Leipzig University \\ rainer.alt.@uni-leipzig.de
}

\author{
Alfred Zimmermann \\ Reutlingen University \\ alfred.zimmermann@ \\ reutlingen-university.de
}

\begin{abstract}
Assistant platforms are becoming a key element for the business model of many companies. They have evolved from assistance systems that provide support when using information (or other) systems to platforms in their own. Alexa, Cortana, or Siri may be used with literally thousands of services. From this background, this paper develops the notion of assistant platforms and elaborates a conceptual model that supports businesses in developing appropriate strategies. The model consists of three main building blocks, an architecture that depicts the components as well as the possible layers of an assistant platform, the mechanism that determines the value creation on assistant platforms, and the ecosystem with its network effects, which emerge from the multi-sided nature of assistant platforms. The model has been derived from a literature review and is illustrated with examples of existing assistant platforms. Its main purpose is to advance the understanding of assistant platforms and to trigger future research.
\end{abstract}

\section{Introduction}

Voice assistants such as Amazon's Alexa, Google's Assistant, Microsoft's Cortana, and Apple's Siri have spread over the past years and provide access to an increasing number of services [1]. Their origin are voicebased systems that enable the interaction with an information system via the most natural form of communication, being the (spoken) human language [2]. Voice and text interfaces are a means to access a specific service (e.g., the check of inventory levels via headphones in stores or the input of commands in operating systems such as Microsoft Windows) and to enter data into a system. While this might already be regarded as an assistant interface, there was little interaction in these systems [1].

A significant step towards more interactivity came with the link to workflow systems in process management. These systems formalized the steps that occurred during the interaction in many customer processes (e.g., in sales and service) and supported more comprehensive question-answer chains. The most powerful step in evolution, however, may be seen in the above-mentioned general-purpose voice assistants. Although they were developed to access the services of a certain provider (e.g., Apple, Google) at first, they meanwhile encompass a universe of specific functionalities (skills) that were developed by third-party providers. Available research has already investigated several aspects of these systems; for example, the speech comprehension capabilities of Alexa and Google [1] and a comparison of the user experience [2]. This paper contributes to this body of knowledge by recognizing that the nature of these assistance and assistant systems has evolved to assistant platforms.

Assistant platforms support users with a variety of tasks and differentiate in this way from applications that provide functionality for a specific purpose [3]. They also have more access points than previous types of voice interfaces and use sensors and actuators. In this way, they have access to an ever-increasing volume of data that may be used for assisting the user. The growth is also reflected in the number of third-party applications: Amazon's Alexa universe already comprises 47000 applications, which are referred to as "skills" [4]. This increase is also linked to a growth of application fields and interaction modes, which explains why assistant platforms are also recognized as general-purpose technologies [5]. They have additional interaction possibilities by integrating visual information such as images and videos into their interactions. Furthermore, assistant platforms associate devices outside their original platform such as TV sets and even microwave ovens. Thus, it may be said that voice is joining the three transformative technologies that drive the rise of conventional platforms: cloud, social and mobile [6].

In view of the increasing dissemination of assistant platforms, adopting them has almost become a competitive necessity for many companies [7]. However, designing a platform is a delicate task, and not surprisingly, a large percentage of platforms have failed [8]. On the other hand, ignoring the effects of platform creation and the emergence of ecosystems enables external 
players to disrupt traditional markets [9]. Therefore, creating an assistant platform strategy is becoming vital for many businesses [10].

To develop an appropriate strategy for their engagement on assistant platforms, this paper argues that three building blocks need to be considered: an architecture, which shows the main functional layer of assistant platforms, the dynamics of value creation mechanisms on assistant platforms, and the drivers of network externalities on these platforms. This leads to the following research questions:

RQ: What are the main characteristics of assistant platforms and what are the important building blocks of a conceptual model of assistant platforms

We answer this main research question by investigating the following sub-research questions.

RQ 1: What is the architecture of assistant platforms?

RQ 2: How is value created on assistant platforms?

RQ 3 What ecosystem and network effects could be supported by assistant platforms?

To answer the research questions, a design science approach is adopted. After presenting the theoretical background and the research method, we develop a conceptual model for assistant platforms to answer the first research question. It depicts the ecosystem and architecture of assistant platforms. We address the second research question with investigations on value generation on assistant platforms. In the following chapter, we develop further questions for future research on assistant platforms to address the third research question.

\section{Research Method}

We combine two approaches for our design science research methodology. We first conducted a systematic literature search to analyze relevant contemporary sources from the most important conference papers and journals as a basis for our conceptual design. We consider our fundamental conceptual models developed from this as part of a grounded theory and our contribution to the topic - value creation on Assistant Platforms. For this purpose, we have applied the research methodology Design Science, according to Johannesson and Perjons [11], in a way that is adapted to our task. In accordance with the research framework of methodology Johannesson and Perjons [11] we have planned the following principled activity phases:

The problem we are explicating is the representation of value creation on assistant platforms. So far, research has its focus on the language-based interface. For the development of initiatives and strategies of companies, however, a comprehensive understanding of the architecture, value creation, and ecosystem of assistant platforms is necessary. Our goal is to create a comprehensive conceptual model of assistant platforms.

In order to achieve the goal of a conceptual model of assistant platforms, we proceed as follows. First, we create an architectural model of assistant-based platforms. We combine this with a value co-creation model based on service-dominant logic (SDL) to describe the assistant platform-based value co-creation. An ecosystem model of assistant platforms is the basis for the network effects. We then do a cross-case evaluation of our findings.

Following Jetu and Riedl [12], a conceptual model will be developed to reveal additional insights since this creates meta-knowledge, which is more than the sum of its parts. The adopted perspective of the present conceptualization is that of the service dominant logic and architecture, which conceives assistant platforms to consist of an architecture, a value co-creation logic, and an ecosystem with network effects.

We concentrate on platforms and have a narrower focus than the investigations on language systems in general (e.g. [1]), where a model for value co-creation is developed from an affordance perspective. These research approaches also integrate non-platform technologies. Therefore, they do not capture platform-specific ways of value creation. There is also research with a narrower focus. For example, the value created may be seen from the end user or the platform provider [13]. The research in [14] targets the interaction with the user and omits the value creation through interaction with other user groups and network effects within as well as between the user groups.

\section{Literature Review and Theoretical Back- ground}

The literature on assistant platforms presents a diverse picture, which is already reflected in the various definitions and notions of assistants (see [15], [16], [17]). Besides the most popular terms of virtual and personal assistants (see Table 1), similar terms are digital, intelligent and voice assistants as well as (less popular) combinations such as intelligent virtual assistants [18], intelligent personal assistants [17], personal digital assistants [19], virtual digital assistants [20] or smart personal assistants [16]. Among the main ideas of these terms are (1) the support of (human) users when (2) accessing digitally enabled services by (3) means of text, voice, and/or visual modes of input. An emphasis on advanced interaction functionality emerges from the adjectives "intelligent" or "smart" and suggests the application of artificial intelligence algorithms. This is reflected in the interaction with a system that simulates the conversation with a human user. Various degrees are possible here as reflected in the degrees of automation 
suggested by [21]. They distinguish seven levels, which reach from no autonomy to full autonomy. The most primitive stage denotes that assistants only recognize and execute defined actions from the users, while the most advanced stage requires that the system to be able to autonomously conduct even complex interactions with users (see also [22]). These stages reflect the evolution that has taken place over the years since the early days of voice and speech recognition in the 1980s and 1990s (e.g. [23]). In parallel, the activities that may be handled by such assistant systems have grown. In this vein Zhou [20] (2016, p. 53) lists ten functions or capabilities: searching, sensing, exploring, adapting, communicating, analyzing, solving, negotiating, deciding and learning.

The main findings from the literature review are, on the one hand, that most research has occurred in the areas of assistant as well assistance systems and that only little research exists regarding assistant platforms. Remarkably, in comparison to the little coverage of assistant platforms in the academic literature, several patents may be found (e.g. [24]). Based on this, we argue that assistant platforms are different from assistance systems, assistant systems, and chatbots: (1) Assistance systems give the human being assistance in a particular context, e.g. vehicle assistance systems support the driver during a ride with the car [25]. (2) Assistant systems have a broader scope and support the human being in multiple contexts. One of the most prominent early examples is Siri (e.g., [26], [27]). (3) Chatbots [22] are dialog-oriented information systems that accept human speech as input and provide speech as output. Although early definitions of chatbots considered both text and speech, chatbots are associated with text input and output. Chatbots are often application or domain-specific. This differentiates them from (virtual, intelligent, personal, or smart) assistants that are domain independent.

Table 1: Literature Search (* peer reviewed ** preview only excluded)

\begin{tabular}{|c|c|c|c|c|c|c|c|c|c|}
\hline & \multicolumn{9}{|c|}{ Search term } \\
\hline 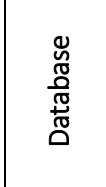 & 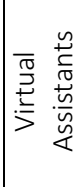 & 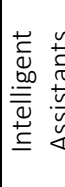 & 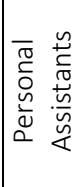 & 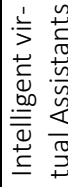 & 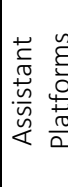 & 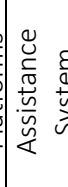 & 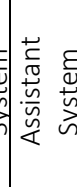 & 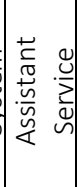 & 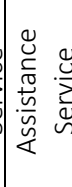 \\
\hline Ebsco & 1130 & 20 & 1239 & 22 & 3 & 393 & 64 & 63 & 375 \\
\hline Ebsco $*$ & 63 & 4 & 84 & 3 & 0 & 169 & 34 & 4 & 34 \\
\hline $\begin{array}{l}\text { Springer } \\
\text { Link }\end{array}$ & 1025 & 984 & 4430 & 42 & 55 & 8452 & 1833 & 297 & 2165 \\
\hline $\begin{array}{l}\text { Spriner } \\
\text { Link ** }\end{array}$ & 293 & 353 & 1352 & 15 & 14 & 5249 & 1177 & 185 & 1318 \\
\hline AISel & 120 & 75 & 257 & 14 & 10 & 229 & 229 & 85 & 85 \\
\hline
\end{tabular}

Although the term assistant platform was little present in the literature, there is a broad body of knowledge on (digital) platforms since the platform model is not new and has already seen several phases or waves. The first dates back to the early days of computing in the 1960s when electronic markets emerged in specific industries, such as agriculture, banking, retail, and tourism. A powerful second wave of platform-oriented companies followed in the mid-1990s and gave birth to nowadays dominant players like Amazon, Alibaba, and Rakuten. They slowly enhanced their product scope and now cover a broad range of offerings. A further wave of platforms has been created in 2010, such as AirBnB and UBER, with a clear transactional focus. The analysis of 200 unicorns in 2017 found that $60 \%$ to $70 \%$ of them were platform businesses, which led the authors to coin the term platformania [28]. A comprehensive review of platforms and a conceptually and empirically grounded taxonomy is presented in [8] and [6]. They are referred to as digital platforms if they provide digital offerings using digital services [29], if they utilize an ecosystem of autonomous agents to co-create value [30] and if they use a repository of business, data and infrastructure services to configure digital offerings [29]. Assistant platforms may be conceived as hybrid platforms since they contain traits both of innovation and transaction platforms. They are innovative in nature because they facilitate the development of services and products complementary to the technological basis provided by the platform. At the same time, assistant platforms also own traits of transaction platforms because they enable transactions between the platform participants.

\section{Conceptual Model}

Our development of a conceptual model for assistant platforms adopts a theoretical framework based on the fundamentals of SDL [31]. Among the key concepts of SDL to explain value creation are resource liquefaction, resource density, resource integration, and actor to actor networks [32].

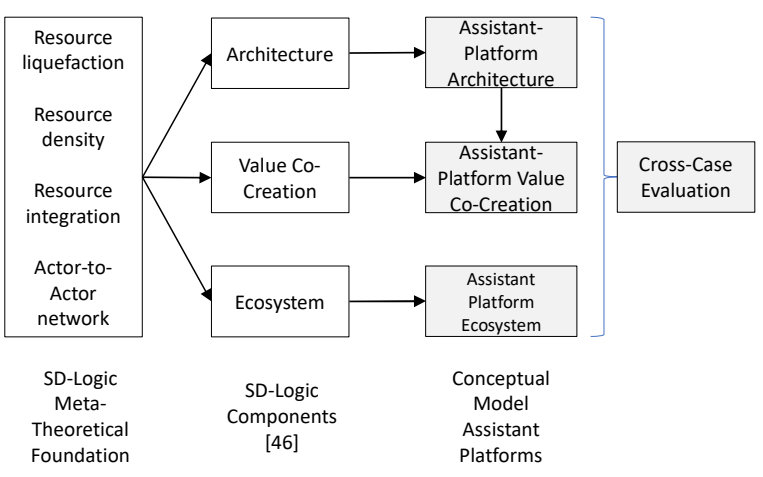

Figure 1: Research Approach and Contributions 
They are used to build general SDL-based concepts for value co-creation and service ecosystems platforms. Furthermore, we use the SDL-based architectures described in [33] and [34]. Both concepts lead to an architecture for assistant platforms, the dynamics of value cocreation, and the network effects in ecosystems surrounding assistant platforms.

The creation of value has been investigated with different perspectives. Lusch and Nambisan [32] provide the most advanced SDL-based model of platforms: platforms support value co-creation by enabling participants to present value-proposition and exchange services.

Resource liquefaction designates the decoupling of information from its physical form or device [35]. Information that is embedded in a physical object cannot be shared easily due to the necessary physical transport [32]. Digitalization enables resource liquefaction [32]. E.g. platforms support resource liquefaction by providing means for describing services [30].

Resource density designates the easy access to appropriate resource bundles [32]. Resource density is maximized when the best combination of resources is used in a particular situation [32]. Platforms increase resource density by accelerating the matching between the actors [36].

Resource integration is fundamental to innovation and performed by all social and economic actors[32]. There are two reasons why actors integrate resources [32]: First, resources have to be combined with other resources for usefulness. Second, innovation is the result of combining existing resources [37]. E.g. resource integration on platforms makes hitherto non-market facing resources available for service exchange [32].

Actor to Actor networks Platforms are described as an emergent actor to actor (A2A) structure that offers an organizing logic for the actors to exchange service and co-create value [32]

Platform architecture is the conceptual specification of interfaces that define a relatively stable platform and a complementary, dynamic set of modules [38]. Furthermore, the platform architecture governs the interactions between the components [38].

The concept of value co-creation is based on a network-centric perspective [32] understanding that all actors in an integration contribute value by resource integration and service provisioning [39]. This perspective breaks with the thinking that there is a strict separation of produce and consumer, that either create or destroy value [32]

Platform ecosystems are the platform and the network of complementarians that enhance platform value by producing complements [40]. Platforms are embedded in a comprehensive ecosystem [41] that is provisioning complementary offerings. [42].

\subsection{Architecture of Assistant Platforms}

Similar to other service platforms (e.g. in the area of e-commerce [43]), the architecture of assistant platforms consists of various building blocks. However, they differ in one important aspect. While the collaboration or workflow aspect is reflected in a coordination and the capability layer reflects the various services (or functionalities) offered on the platform, the integration, and the cognition layers are proposed as enhancements regarding existing service platform architectures (see Figure 2).

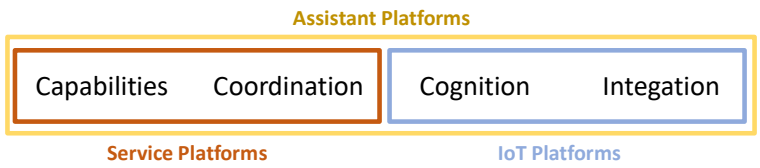

\section{Figure 2: Assistant Platforms}

They highlight that assistant platforms may be seen at the intersection to Internet of Things (IoT) platforms [44], which envisage the coupling of various electronic devices (e.g. sensors) and an "intelligent recognition framework" [43].

However, their role as assistant platform makes them differ in one important aspect. While the collaboration or workflow aspect is reflected in a coordination and the capability layer reflects the various services (or functionalities) offered on the platform, the integration, and the cognition layers are proposed as enhancements regarding existing service platform architectures.

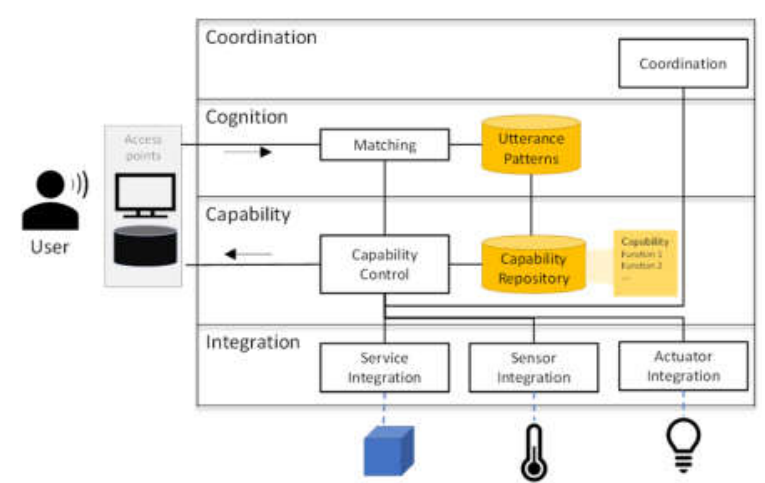

Figure 3: Assistant Platform Architecture

At first, the voice uttered by users is grasped in the cognitive layer and mapped towards capabilities, which are provided by the assistant platform [45]. These capabilities are materialized in form so-called "skills“ (Alexa) [46] or ,actions“ (Google) [47]. From a SDL point of view, these capabilities are service propositions. Capabilities are set of functions the user can invoke. After identifying the closest matching capability, the platform translates the user utterance into a proper call of the capability's functionality. This functionality may access internal or external services, sensors, and actuators. 
A rather new layer is the coordination layer, which coordinates the execution of multiple capabilities either on the user's request or triggered by events. Based on the architectural description of assistant platforms, the impact of assistant platforms on resource liquefaction and resource density is investigated, the results are summarized in Table 2.

Cognitive Layer. Assistant platforms pursue a strategy of ubiquity in the user's environment. They provide a multitude of access points to the user that capture utterances of the user. In addition to primary devices such as the "Echo" devices on the Alexa platform from Amazon assistant platforms can also be accessed on host devices such as TV sets and even microwave ovens. The cognition is activated by wake words or sentences. After activation, the device streams the user's speech to a matching mechanism that compares the utterance of the user with a set of predefined utterances provided by the developers of the capabilities. The matching mechanism identifies the user utterance with the closest fitting utterance pattern. In this way, the most probable capability is selected. Control is then given to capability control in the capability layer.

The use of a voice-interface means that the user does not have to learn additional skills such as using a mouse or a touchscreen. A high number of devices providing access to the assistant platform also increases the liquefaction of resources integrated into the assistant platform. Resource liquefaction is increased by easing the access to resource information via a voice-based interface and increasing the number of devices the resource information is accessible on. Resource density is increased because, contrary to traditional interfaces, voice-based interfaces are able to capture the user's request using a set of utterances and not only a predefined phrase.

Capability Layer. The capability layer processes the user requests identified by the cognition layer in the capability control component. The capability control component accesses the capability repository [7] that contains capabilities provided by capability developers. The selected capability processes the requests identified by the cognition layer and creates a response that is returned to the user. The reaction of the skill can be to perform an action or to send a voice message. Capabilities on assistant platforms have one or more individual functions that together represent the functionality of the capability. It is also possible to enter parameters into the patterns defining the user requests.

Integration Layer. The integration layer provides the integration of services, sensor device, and actuators. Furthermore, assistant platforms integrate sensor and actuators. The assistant platform integrates both internal and external services. Internal services are provided by the platform sponsor. E.g., Google Assistant has access to the user's calendar. External services are provided by third party vendors. E.g., weather reports are provided by external service providers on most assistant platforms. Sensor devices enable service to perceive the environment of the user. For example, it is possible to measure temperature, humidity, etc. and there are cameras and motion detectors that can be easily integrated into assistant platforms. There may be multiple sensor devices e.g., to measure the temperature in all rooms of the user's house. Actuators impact the environment of the user. For example, LED lightbulbs are increasingly provided with an interface that enables their integration into assistant platforms.

Coordination Layer. The coordination layer is the newest in the large platforms so far, but its further development is already apparent. It can be considered as customer induced service-coordination [48]. For example, the Google Assistant platform has a mechanism to link several services with each other. Up to now, this mechanism only provides sequential processes. However, it is obvious that this orchestration mechanism can easily be extended to complex control flows. In particular, it is conceivable that the execution of coordination is made dependent on the state of variable events or the occurrence of certain events.

Table 2: Assistant Platform Value Creation

\begin{tabular}{|c|c|c|}
\hline Layer $\begin{array}{r}\text { Service } \\
\text { Co-Creation }\end{array}$ & $\begin{array}{c}\text { Resource } \\
\text { Liquefaction }\end{array}$ & Resource Density \\
\hline Cognition & Voice-based interface & $\begin{array}{l}\text { Matching of non-exact } \\
\text { user utterances }\end{array}$ \\
\hline Capability & $\begin{array}{l}\text { User ratings } \\
\text { Usage pattern }\end{array}$ & $\begin{array}{l}\text { User-provided content } \\
\text { Service selection } \\
\text { Function selection }\end{array}$ \\
\hline Integration & $\begin{array}{c}\text { Services, sensors and } \\
\text { actors become acces- } \\
\text { sible / integration } \\
\text { graph }\end{array}$ & $\begin{array}{c}\text { Context-information on } \\
\text { service / actuator / sen- } \\
\text { sor usage patterns and } \\
\text { trends }\end{array}$ \\
\hline Coordination & $\begin{array}{c}\text { Orchestration } \\
\text { patterns }\end{array}$ & $\begin{array}{c}\text { Parametrization of } \\
\text { services }\end{array}$ \\
\hline
\end{tabular}

\subsection{Value Co-Creation}

Value co-creation has been identified as common to successful platforms [49] and investigated in depth in [32]. Value co-creation as a dominant logic of information system design has been investigated in [50]. It has also been investigated in business to business settings [30]. SDL provides a model to analyze value cocreation [32]: the exchange of services between actors that integrated resources is the foundation of value cocreation [51].To support our research, we develop a value co-creation-based conceptualization of assistant platforms. Assistant platforms can be interpreted as service platform that are enhancing the efficiency and effectiveness of service exchange by resource liquefaction and increasing resource density [32], as shown in Figure 4. 


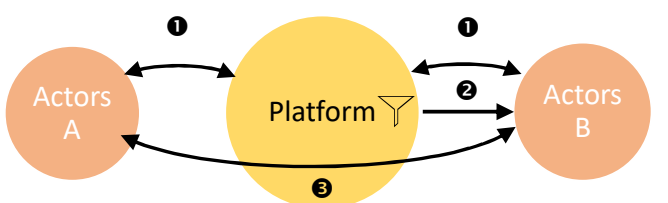

Figure 4: Assistant Platforms as value co-creation mechanisms

Starting point is the exchange of information on value propositions (1). Assistant platforms also filter value propositions (2). After a value proposition is accepted, platforms enable the exchange of services and currencies (3).

Exchange of Value Propositions. The exchange of value propositions on assistant platforms is done on different layers. On the capability layer, the vendors of capabilities provide the definition and implementation of capabilities in the capability registry. Social production [52] plays a central role in the exchange of value propositions. Most capabilities do not emerge according to the specifications of the platform operator but on the initiative of the independent developers. The vendors of services, actuators, and sensors integrate their services and devices on the integration layer by providing comprehensive configuration information. The cognition layer is used by users to exchange their value proposition by requesting capabilities. Finally, capability requests demanding non-existent capabilities provide important hints for the further development of capabilities.

\section{Table 3: Value Co-Creation}

\begin{tabular}{|c|c|c|c|}
\hline $\begin{array}{r}\text { Service Co- } \\
\text { Creation }\end{array}$ & $\begin{array}{c}\text { Exchange of Value } \\
\text { Propositions }\end{array}$ & Filtering & $\begin{array}{c}\text { Service } \\
\text { Exchange }\end{array}$ \\
\hline Cognition & Capability requests & $\begin{array}{c}\text { Two-Step recog- } \\
\text { nition }\end{array}$ & Usage patterns \\
\hline Capability & $\begin{array}{c}\text { Capability descrip- } \\
\text { tion and implemen- } \\
\text { tation provided }\end{array}$ & $\begin{array}{c}\text { User registers } \\
\text { subset of availa- } \\
\text { ble capabilities }\end{array}$ & $\begin{array}{c}\text { Reviews and } \\
\text { comments on } \\
\text { capabilities }\end{array}$ \\
\hline & $\begin{array}{c}\text { Configuration of } \\
\text { comprehensive / } \\
\text { integral services / } \\
\text { service package }\end{array}$ & $\begin{array}{c}\text { Registration of a } \\
\text { subset of ser- } \\
\text { vices and de- } \\
\text { vices }\end{array}$ & $\begin{array}{c}\text { Usage of ser- } \\
\text { vices and de- } \\
\text { vices. }\end{array}$ \\
\hline Coordination \\
$\begin{array}{c}\text { Individual configu- } \\
\text { ration and exten- } \\
\text { sion of service } \\
\text { proposition }\end{array}$ & $\begin{array}{c}\text { Extension of co- } \\
\text { ordination / or- } \\
\text { chestration }\end{array}$ & $\begin{array}{c}\text { Usage of } \\
\text { coordination }\end{array}$ \\
\hline
\end{tabular}

Filtering. The evaluation of data on the overall use of skills is a source of valuable information. In addition, the skills which are typically used together can be identified and their order described. This data can be used to develop a recommendation system that makes suggestions to the user for additional kills to be activated. Furthermore, in this way, developers are able to detect which services and functions are important to the users. From the frequency of use and the use of partial functionalities, important information for the further development of the skills can be collected.

Service Exchange. From the frequency of use and the use of partial functionalities, important information for the further development of the skills can be collected. The evaluation of data on the overall use of capabilities can provide important information.

It is possible to identify which skills are typically activated by which user types and to determine which capabilities are typically used together and in which order. Furthermore, in this way, developers are able to detect which services and functions are important to the users.

\subsection{Assistant Platform Ecosystem}

Assistant platforms aspire to support users in their daily private or business activities. The large platforms Alexa, Google Assistant, and Cortana differ in the type of users they address. Alexa has the strongest consumer focus, whereas Cortana shifts its focus to the professional user. Google assistant has a focus between both other platforms. Despite these differences, all platforms may be seen as multi-sided in nature and, thus, underlying network effects as important value creation logic [29]. Network effects may be effective both for other user groups and for your user group. Network effects on assistant platforms describe the effect that the value of a service changes with the number of consumers of the service [1]. They arise both within the user groups of assistant platforms and between the different user groups of assistant platforms. In the assistant platform ecosystem, the assistant platforms enable interactions between users and several complementors. Service providers integrate external resources such as information and services and create a language-based interface for them. Information and services are provided by a large number of ecosystem participants, but they usually do not appear directly on the assistant platform.

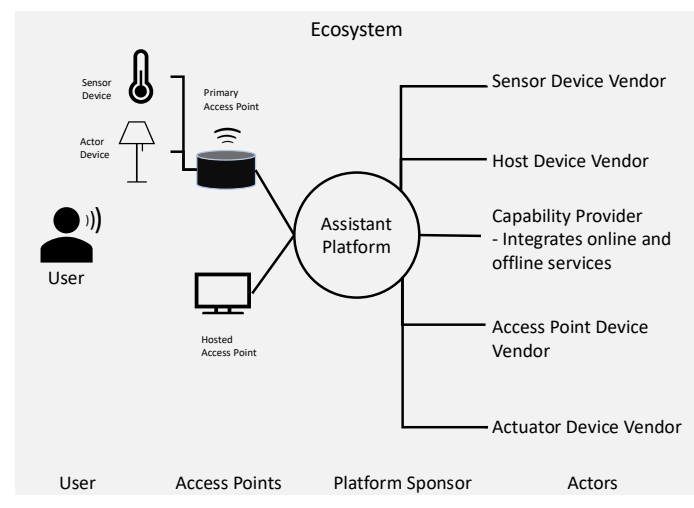

Figure 5: Assistant Ecosystem 
The two main categories of network effects [29] may be found with assistant platforms. Direct network effects are created within one group of actors only [28] . Indirect network effects are created by one group of actors and impact another [28]. Positive network effects influence the value of services and products created positively as more actors join the system [29]. For example, additional actors increase the number of potential transaction partners. Negative network effects influence the value of services and products created negatively as more actors join the system [29]. This is the case as a large number of actors increases the search effort.

Direct network effects are created in the different actor groups as follows. For the users, the assistant platform becomes more interesting due to a higher number of other users because there are more possibilities for communication. Also, the capability providers achieve direct network effects by improving the speech recognition that occurs when there are more different capability providers on the platform. Furthermore, the increasing number of developers also increases the exchange of ideas and knowledge between them, communities already were created, books on service development already published. The access device providers benefit from a higher market coverage on the one hand, and from complementary providers, on the other hand, there is an intensification of competition. The same applies to the sensor and actuator providers.

Table 4: Direct and Indirect Network Effects

\begin{tabular}{|c|c|c|c|c|}
\hline From & User & $\begin{array}{l}\text { Capability } \\
\text { Provider }\end{array}$ & $\begin{array}{l}\text { Access } \\
\text { Device } \\
\text { Provider }\end{array}$ & $\begin{array}{c}\text { Service, Sen- } \\
\text { sor, Actuator } \\
\text { provider }\end{array}$ \\
\hline User & $\begin{array}{l}\text { Communica- } \\
\text { tion with fel- } \\
\text { low users }\end{array}$ & $\begin{array}{l}\text { Increased } \\
\text { demand } \\
\text { Improved } \\
\text { recognition }\end{array}$ & $\begin{array}{l}\text { Increased } \\
\text { demand }\end{array}$ & $\begin{array}{l}\text { Increased } \\
\text { demand }\end{array}$ \\
\hline $\begin{array}{l}\text { Capability } \\
\text { provider }\end{array}$ & $\begin{array}{l}\text { Increases at- } \\
\text { tractivity } \\
\text { Increase } \\
\text { lock-in Exit } \\
\text { costs in- } \\
\text { creases }\end{array}$ & $\begin{array}{l}\text { Quality of } \\
\text { speech } \\
\text { recognition } \\
\text { Parameter } \\
\text { association }\end{array}$ & $\mid \begin{array}{ll}\text { Creates In- } \\
\text { centive to } \\
\text { buy device }\end{array}$ & $\begin{array}{l}\text { Creates In- } \\
\text { centive to } \\
\text { buy device }\end{array}$ \\
\hline $\begin{array}{l}\text { Access De- } \\
\text { vice Pro- } \\
\text { vider }\end{array}$ & $\begin{array}{l}\text { Increases at- } \\
\text { tractivity }\end{array}$ & $\begin{array}{l}\text { Increases } \\
\text { Touchpoint, } \\
\text { more data } \\
\text { and actions }\end{array}$ & $\begin{array}{l}\text { Better mar- } \\
\text { ket coverage }\end{array}$ & $\begin{array}{l}\text { Comple- } \\
\text { mentors }\end{array}$ \\
\hline $\begin{array}{c}\text { Service, } \\
\text { Sensor, Ac- } \\
\text { tuator Pro- } \\
\text { vider }\end{array}$ & $\begin{array}{l}\text { Increases at- } \\
\text { tractivity }\end{array}$ & $\begin{array}{l}\text { Provides } \\
\text { more data }\end{array}$ & $\begin{array}{l}\text { Comple- } \\
\text { mentors }\end{array}$ & $\begin{array}{l}\text { Better mar- } \\
\text { ket coverage }\end{array}$ \\
\hline
\end{tabular}

Indirect network effects emerge, if the increase in participants in one actor group has effects in other participant groups. For example, an increase in the number of users improves recognition of the functionalities offered by the capability providers. The recognition performance of speech recognition systems grows with number of different users and their frequency of interaction with the assistant platform. Another network effect of the assistants impacts the similarity assessment of terms that are used as possible parameters for queries. As more users are using the assistant platform, the association of terms towards parameters of the service requests increases.

The providers of access devices, sensors, and benefit from an increased demand from more users. First, an increased number of capability providers makes the system more attractive to users. The presence of a sufficiently large number of skills means that the end users can cover their daily processes completely with the skills of a platform. This creates a significant exit barrier for the consumers who would have considerable switching costs in the form of reconfiguration of skills and possibly also the purchase of new skills if they switched to another platform this year. The presence of more capabilities leads to an increased demand for access devices, sensors, and actuators.

Second, a larger number of access devices increases the attractiveness of the platform for the users and provides an increased number of access points for the capability providers. For the providers of sensors and actuators, network effects arise from complementary offers. The availability of more sensor devices increases the attractiveness of the platform for users and improves the data supply to the capability providers. By combining the information from multiple integrated devices, it is possible gain additional goals for different goals [9]. Access device providers and actuators also benefit from the larger number of sensors through complementarities. The availability of more sensor devices increases the attractiveness of the platform for users and improves the data supply to the capability providers. By combining the information from multiple integrated devices, it is possible gain additional goals for different goals [9]. Access device providers and actuators also benefit from the larger number of sensors through complementarities. A larger number of actuators increases the attractiveness of the platform for users and, improves the capability provider's ability to influence the user environment. There are complementary effects with both access devices and sensors.

\section{Cross-Case Evaluation}

Large assistant platforms such as Alexa and Google Assistant address different purposes. For example, assistant platforms support users at home by providing access to useful information and home automation. In a professional context, assistant platforms increase the efficiency of interaction by providing facilitated access to administrative functionality such as calendars and to-do lists. The following presents an early evaluation using 
Amazon Alexa and Google Assistant. It is based on the developer documentation of Alexa [46] and the Google Assistant [47]. Since Apple Siri App does not open to third-party vendors, it falls outside the definition of platforms as to how to use them. Similarly, Cortana is excluded since it is moving its focus from a general to a specialized platform or assistance system.

\subsection{Architecture}

At present, Amazon Alexa is limited to proprietary access points, whereas Google Assistants uses a mixture of proprietary and third-party access points. Both assistant platforms use host devices such as TV sets. The capabilities are named "skills" on the Alexa platform and "actions" on the Google Assistant platform. The number of skills on the Alexa platform is much greater than on the Google Assistant platform that uses a much more selective approach.

Both platform providers facilitate the creation of capabilities considerably. This is done by providing development environments that largely abstract from the technological details and allow a transparent use of the computing resources necessary for the creation of the wizards. In the development of skills, the developers are also supported by the provision of extensive functionality. Thus, for example, standard vocabulary is made available, which significantly accelerates the development of skills. Regarding the integration and coordination layers, both platforms are highly developed. They easily link with a variety of other devices (e.g., Alexa with the Philips' Hue lighting system). On the coordination layer, the Google Assistant Platform seems more open and flexible since it enables the user to define workflows with Google provided capabilities.

\subsection{Value Co-Creation}

To support the exchange of value propositions both Amazon Alexa and Google Assistant support the definition and implementation of capabilities in the capability registry. Vendors of services, actuators, and sensors integrate their services and devices on the integration layer by providing comprehensive configuration information via the Amazon Web Services and the Google Cloud, respectively. Amazon Alexa and Google Assistant differ in the way they filter value propositions of the user. For example, Amazon Alexa uses a two-step approach for all third-party capabilities. The user has first to select the capability then he may choose the functionality in more detail. On the contrary, Google Assistant pursues an integrated approach.

The exchange of value propositions on assistant platforms is done on Amazon Alexa and Google Assistant by the vendors of capabilities through the definition and implementation of capabilities in the capability reg- istry. The vendors of services, actuators, and sensors integrate their services and devices on the integration layer by providing comprehensive configuration information. The cognition layer is used by users to exchange their value proposition by requesting capabilities.

\subsection{Ecosystem}

Both Amazon Alexa and Google Assistant address primarily the end-user and support many capability providers. In comparison, the number of capability provider at Amazon Alexa is considerably larger than that of Google Assistant. Google Assistant also includes thirdparty access device providers, such as Lenovo. Both ecosystems embrace many providers of services, sensors, and actuators.

Table 5: Comparison of Amazon Alexa and Google Assistant

\begin{tabular}{|l|c|c|}
\hline & Amazon Alexa & $\begin{array}{c}\text { Google } \\
\text { Assistant }\end{array}$ \\
\hline Capabilities & Skills & Actions \\
\hline $\begin{array}{l}\text { Coordination } \\
\text { Layer }\end{array}$ & No & Yes \\
\hline Filtering & Two steps & One step \\
\hline
\end{tabular}

\section{Discussion and Conclusions}

This research conceptualized the virtual assistants that are increasingly becoming an element of many products and services. They have evolved from voicebased assistant systems at the frontend of large digital platforms towards platforms in themselves. As a mechanism for service delivery and value creation, the respective assistants for example, Alexa or Google Assistant act as mediators of services. An important element in this process is the ability for third-party service providers to develop their own interaction routines and store them on the assistant platform. The functionality is represented to a very high degree by the services or skills provided by third-party providers and is not a direct component of the assistants, which is recognizable by the fact that skills can be added, modified, and removed at will. This differentiates this research from other works such as [53], which use a broader definition of assistants and which would not qualify as platforms. In this case, however, the skills are often part of the assistant and cannot be created by third parties. Using established theory from SDL and architecture, the concept in this paper has been developed for assistant platforms that comprises three elements: an architecture, a valueco-creation logic, and the ecosystem. They promise to advance existing research in several directions.

First, the four-layer architecture is different from existing digital platforms due to the speech-interaction functionalities and the integration of various smart de- 
vices. In this respect, assistant platforms combine elements of service and IoT platforms, which point towards an additional type of platforms as a basis for discussion in future research.

Second, the value-co-creation logic of SDL is applicable to assistant platforms and may be described on the four layers of the architecture. The four architecture layers impact the phases of value co-creation exchange of value proposition, filtering, and service exchange in varying degrees.

Third, assistant platforms are ecosystems in themselves with their own dynamics. This implies that in addition to the network effects, which are present on the platforms of the assistant providers (e.g., the Apple AppStore), additional network effects need to be distinguished with the assistant platforms. Investigating the interplay between these multiple network effects points to another field for future research.

It is increasingly important for companies to understand the value creation mechanisms on assistant platforms and use them to create value for their customers. Previous research in the field of platforms has found it difficult to access strong technology-driven platforms such as the AI Assistant because of their emergent nature. We evaluate our findings with a cross-case evaluation based on two important assistant platforms, Amazon Alexa, and Google Assistant. Assistant platforms are not a theoretically developed concept but have been created by a multitude of technological and market-oriented decisions. These decisions are difficult to capture with the traditional means of information systems research that are adapted to tayloristic information systems architectures. Instead, we assume that the development of assistant platforms is strongly driven by concepts such as social production. Therefore, we consider our research as the first step towards a conceptualization of assistant platforms and shall pave the way for further research also in the development of methods for information systems research.

\section{References}

[1] López, G., L. Quesada, and L.A. Guerrero, “Alexa vs. Siri vs. Cortana vs. Google Assistant: a comparison of speech-based natural user interfaces", International Conference on Applied Human Factors and Ergonomics, Springer (2017), 241-250.

[2] Berdasco, A., G. López, I. Diaz, L. Quesada, and L.A. Guerrero, "User Experience Comparison of Intelligent Personal Assistants: Alexa, Google Assistant, Siri and Cortana", Proceedings 31(1), 2019, pp. 51.

[3] Bodart, A., and C. Condon, "Virtual assistant US. Pat. No. US20070043687A1", 2007.

[4] Major, D.J., D.Y. Huang, M. Chetty, and N. Feamster, "Alexa, Who Am I Speaking To? Understanding Users'
Ability to Identify Third-Party Apps on Amazon Alexa", arXiv preprint arXiv:1910.14112, 2019.

[5] Helpman, E., General purpose technologies and economic growth, MIT press, 1998

[6] Choudary, S.P., and M. Bonchek, "Three Elements of a Successful Platform Strategy", Harvard Business Review, 2013. https://hbr.org/2013/01/three-elements-of-asuccessful-platform

[7] Alt, R., and H.-D. Zimmermann, "Electronic Markets on platform competition", Electronic Markets 29(2), 2019, pp. 143-149.

[8] Yoffie, D.B., A. Gawer, and M.A. Cusumano, "A Study of More Than 250 Platforms Reveals Why Most Fail", Harvard Business Review, 2019, pp. 5.

[9] Subramaniam, M., B. Iyer, and V. Venkatraman, "Competing in digital ecosystems", Business Horizons 62(1), 2019, pp. 83-94.

[10] Wan, X., J. Cenamor, G. Parker, and M. Van Alstyne, "Unraveling platform strategies: A review from an organizational ambidexterity perspective", Sustainability 9(5), 2017, pp. 734-752.

[11] Johannesson, P., and E. Perjons, An Introduction to Design Science, Springer International Publishing, 2014.

[12] Jetu, F., and R. Riedl, "Determinants of Information Systems and Information Technology Project Team Success: A Literature Review and a Conceptual Model", Communications of the Association for Information Systems 30(1), 2012, pp. 456-482.

[13] Rzepka, C., "Examining the Use of Voice Assistants: A Value-Focused Thinking Approach", AMCIS 2019 Proceedings, (2019), 10.

[14] Rzepka, C., B. Berger, and T. Hess, "Why Another Customer Channel? Consumers' Perceived Benefits and Costs of Voice Commerce", Proceedings HICSS 53, (2020), 4079-4088.

[15] Perez Garcia, D.M., S. Saffon Lopez, and H. Donis, "Everybody is talking about Virtual Assistants, but how are people really using them?", Proceedings BHCI-2018, BCS Learning \& Development (2018), 1-5.

[16] Knote, R., "Towards Smart Assistance Systems for Physical and Manual Tasks", Proceedings of the 27th European Conference on Information Systems (ECIS), (2019).

[17] de Barcelos Silva, A., M.M. Gomes, C.A. da Costa, et al., "Intelligent personal assistants: A systematic literature review", Expert Systems with Applications 147, 2020, pp. 113193.

[18] Maier, T., J. Menold, and C. McComb, "Towards an Ontology of Cognitive Assistants", Proceedings of the Design Society: International Conference on Engineering Design, Cambridge University Press (2019), 2637-2646.

[19] Jonathan, O., C. Ogbunude, S. Misra, R. Damaševičius, R. Maskeliunas, and R. Ahuja, "Design and implementation of a mobile-based personal digital assistant (MPDA)", International Conference on Computational Intelligence, Communications, and Business Analytics, Springer (2018), 15-28.

[20] Zhou, D.Z., “A Framework for Virtual Assistants: An exploratory study", International Journal of Social Science and Business 1(4), 2016, pp. 8.

[21] Galdon, F., A. Hall, and S.J. Wang, "Designing trust in highly automated virtual assistants: A taxonomy of levels 
of autonomy", In Artificial Intelligence in industry 4.0. Springer, Cham, 2019, 14.

[22] Sabharwal, N., and A. Agrawal, "New Research in the Field of Cognitive Virtual Chatbots", In Cognitive Virtual Assistants Using Google Dialogflow. Springer, 2020, 183-186.

[23] Baber, C., and K.S. Hone, "Modelling error recovery and repair in automatic speech recognition", International Journal of Man-Machine Studies 39(3), 1993, pp. 495515.

[24] Yadgar, O., N. Yorke-Smith, B. Peintner, et al., "Generic virtual personal assistant platform USA Pat. No. 9,575,964", 2017.

[25] Hegeman, G., K. Brookhuis, and S. Hoogendoorn, “Opportunities of advanced driver assistance systems towards overtaking", European Journal of Transport and Infrastructure Research 5(4), 2020, pp. 281-296.

[26] Aron, J., "How innovative is Apple's new voice assistant, Siri?", The New Scientist(2836), 2011, pp. 24-24.

[27] Naone, E., "TR10: Intelligent Software Assistant", Technology Review, Mar.-Apr, 2009

[28] Eisenmann, T., G. Parker, and M.W. Van Alstyne, "Strategies for two-sided markets", Harvard business review 84(10), 2006, pp. 92.

[29] Shapiro, C., S. Carl, and H.R. Varian, Information rules: a strategic guide to the network economy, Harvard Business Press, 1998.

[30] Hein, A., J. Weking, M. Schreieck, M. Wiesche, M. Böhm, and H. Krcmar, "Value Co-Creation Practices in Business-to-Business Platform Ecosystems", Electronic Markets 29(3), 2019, pp. 503-518.

[31] Lusch, R.F., and S.L. Vargo, "Service-dominant logic: reactions, reflections and refinements", Marketing Theory 6(3), 2006, pp. 281.

[32] Lusch, R.F., and S. Nambisan, "Service Innovation: A Service-Dominant Logic Perspective", MIS Quarterly 39(1), 2015, pp. 155-175.

[33] Weiß, P., A. Zolnowski, M. Warg, and T. Schuster, "Service Dominant Architecture: Conceptualizing the Foundation for Execution of Digital Strategies based on S-D logic", Proceedings of the 51st Hawaii International Conference on System Sciences, (2018), 1630-1639.

[34] Schmidt, R., and A. Kieninger, "DYNSEA-A dynamic service-oriented Enterprise Architecture based on SDlogic", 2009 13th Enterprise Distributed Object Computing Conference Workshops, IEEE (2009), 290-296.

[35] Normann, R., Service Management : Strategy and Leadership in Service Business, 3rd Edition, Wiley, 2001.

[36] Lusch, R., S. Vargo, and M. Tanniru, "Service, value networks and learning", Journal of the Academy of Marketing Science 38(1), 2010, pp. 19-31.

[37] Arthur, W.B., The nature of technology: What it is and how it evolves, Simon and Schuster, 2009.

[38] Tiwana, A., B. Konsynski, and A.A. Bush, "Research commentary-Platform evolution: Coevolution of platform architecture, governance, and environmental dynamics", Information systems research 21(4), 2010, pp. 675-687.

[39] Vargo, S.L., and R.F. Lusch, "It's all B2B... and beyond: Toward a systems perspective of the market", Industrial Marketing Management 40(2), 2011, pp. 181-187.
[40] Ceccagnoli, M., C. Forman, P. Huang, and D.J. Wu, "Cocreation of value in a platform ecosystem! The case of enterprise software", MIS quarterly, 2012, pp. 263290.

[41] Hein, A., M. Schreieck, T. Riasanow, et al., "Digital platform ecosystems", Electronic Markets 30(1), 2020, pp. 87-98.

[42] de Reuver, M., C. Sørensen, and R.C. Basole, "The Digital Platform: A Research Agenda", Journal of Information Technology 33(2), 2018, pp. 124-135.

[43] Aulkemeier, F., M.A. Paramartha, M.-E. Iacob, and J. van Hillegersberg, "A pluggable service platform architecture for e-commerce", Information Systems and e-Business Management 14(3), 2016, pp. 469-489.

[44] Kim, J., Y. Jeon, and H. Kim, "The intelligent IoT common service platform architecture and service implementation", The Journal of Supercomputing 74(9), 2018, pp. 4242-4260.

[45] Maglio, P., S. Vargo, N. Caswell, and J. Spohrer, "The service system is the basic abstraction of service science", Information Systems and E-Business Management 7(4), 2009, pp. 395-406.

[46] "Alexa Developer Whitepapers - Alexa Skills Kit Official Site", /alexa/alexa-skills-kit/get-deeper/whitepapers, https://developer.amazon.com/en-US/alexa/alexa-skillskit/get-deeper/whitepapers

[47] "Google Assistant | Google Developers", https://developers.google.com/assistant

[48] Alt, R., J.F. Ehmke, R. Haux, et al., "Towards customerinduced service orchestration - requirements for the next step of customer orientation", Electronic Markets 29(1), 2019, pp. 79-91.

[49] Smedlund, A., and H. Faghankhani, "Platform Orchestration for Efficiency, Development, and Innovation", 2015 48th Hawaii International Conference on System Sciences, IEEE (2015), 1380-1388.

[50] Haki, K., M. Blaschke, S. Aier, and R. Winter, "A Value Co-creation Perspective on Information Systems Analysis and Design", Business \& Information Systems Engineering 61(4), 2019, pp. 487-502.

[51] Vargo, S., P. Maglio, and M. Akaka, "On value and value co-creation: A service systems and service logic perspective", European Management Journal 26(3), 2008, pp. $145-152$.

[52] Benkler, Y., The Wealth of Networks: How Social Production Transforms Markets and Freedom, Yale University Press, 2006

[53] López, G., L. Quesada, and L.A. Guerrero, “Alexa vs. Siri vs. Cortana vs. Google Assistant: A Comparison of Speech-Based Natural User Interfaces", In I.L. Nunes, ed., Advances in Human Factors and Systems Interaction. Springer International Publishing, Cham, 2018, 241-250. 